\title{
Detection of hypertension in accident and emergency departments
}

\author{
R. N. SLATER, D. J. DACRUZ \& L. N. JARRETT \\ Accident and Emergency Department' Leicester Royal Infirmary, Leicester, England
}

\section{SUMMARY}

Routine blood pressure measurements are performed on all non-ambulatory patients attending the Accident and Emergency Department, Leicester Royal Infirmary, England. However, the patient's general practitioner is not always informed of the reading, even if it is found to be raised. One of the chief reasons for this omission is the fact that single, elevated blood pressure readings taken in an accident and emergency department are considered to be of doubtful significance.

Sixty patients with a single, elevated blood pressure measurement were studied. Fifteen of these patients were found to continue to have an elevated blood pressure measurement when reviewed in a quiet, relaxed environment. Fourteen of these 15 patients are currently being treated for hypertension after independent assessment by their family practitioners.

It was concluded that single, elevated blood pressure readings are useful indicators of hypertension in non-ambulatory patients attending accident and emergency departments. It is, therefore, important to inform general practitioners of incidentally raised blood pressure readings.

\section{INTRODUCTION}

The value of early detection and good management of essential hypertension is well recognised: the risk of stroke is reduced by $43 \%$ (Beevers et al., 1973). Despite this, many epidemiological studies have illustrated inadequacies of detection and management of hypertension (Barlow et al., 1977; Coope, 1984).

This study seeks to determine the value of single, elevated blood pressure measurements in non-ambulatory patients who have been discharged back to the care of their family practitioner following their accident and emergency attendance.

Correspondence: Mr D. F. DaCruz, Senior Registrar, Accident and Emergency Department, Leicester Royal Infirmary, Leicester LE1 5WW, England 


\section{METHOD}

At the Accident and Emergency Department, Leicester Royal Infirmary, all patients? requiring more than the most superficial examination are placed on a trolley or couch and have basic observations, including a blood pressure measurement taken and recorded by a nurse.

The notes of 2000 patients attending the department during the period of a fortnighto in October 1985 were studied. Sixty consecutive patients aged between 25 and 65 with $\stackrel{\overrightarrow{0}}{\overrightarrow{0}}$ co-incidental, single-reading hypertension were identified. Known hypertensives and $\mathbb{Q}$ patients who were admitted to hospital when they first attended were excluded from thein study.

This highly selective group were all noted to have a diastolic pressure of greater than $\vec{\omega}$ $95 \mathrm{~mm}$ of mercury and were recalled.

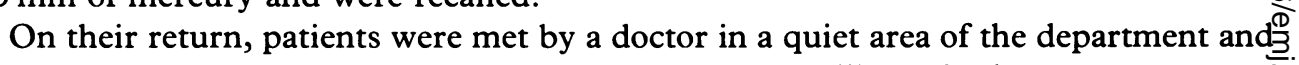
blood pressure measurement was taken using a recently calibrated sphygmomanometer:Patients were semi-recumbant with the elbow at the level of the heart, and their $\vec{r}$ readings were taken by a single doctor using palpation and auscultation (O'Brien et al., 9 1985). Measurements were repeated at $10 \mathrm{~min}$ intervals until consistent readings wereobtained. Both arms were studied. Patients with consistently elevated blood pressure readings were informed of the finding and the relevant information was communicatedō to the family practitioner by post.

\section{RESULTS}

Of the 60 patients recalled, seven defaulted-four because they lived in the outskirts of Leicestershire. None of the defaulters are currently being treated for hypertension by⿳्ञ亏 their GPs.

In the group of 53 patients who did attend, 15 exhibited raised diastolic bloodo pressure readings (greater than $95 \mathrm{~mm}$ of mercury). Fourteen of these patients are now being treated for hypertension after independent assessment by their GPs.

\section{DISCUSSION}

The authors believe that management of hypertension should remain with the family practitioner but that every opportunity should be taken by doctors in other specialitieso to assist in detection of elevated blood pressure. In a busy accident and emergency department, it is tempting to dismiss an incidental high blood pressure reading as being స్ due to factors such as the presenting injury, stressful surroundings and the 'presso effect' of medical staff (O'Brien et al., 1985). This study confirms the value of informinge family practitioners of co-incidental raised blood pressure readings. It does not attemptos to measure the incidence of undetected hypertension in patients attending the accident and emergency department. 


\section{ACKNOWLEDGEMENT}

The authors wish to thank Mr Bodiwala, Consultant in Accident and Emergency, Leicester Royal Infirmary, England, for his assistance with the project.

\section{REFERENCES}

Barlow D. H., Beevers D. G., Hawthorne V. M., Watt H. D. \& Young G. A. R. (1977) Blood pressure management at screening and in general practice. British Heart fournal 39, 7-12.

Beevers D. G., Fairman M. J., Hamilton M. \& Harpur J. E. (1973) The influence of antihypertensive treatment over the incidence of cerebral vascular disease. Postgraduate Medical fournal 49, 905-7.

Coope J. (1984) Hypertension in general practice: what is to be done? British Medical fournal 288, 880-1.

O'Brien E., Fitzgerald D. \& O'Malley K. (1985) Blood pressure measurement: current practice and future trends. British Medical Fournal 290, 729-34.

Received 10 fuly 1986; revised 1 November 1986 